\title{
The Development of Vegetation Indices: a Short Overview
}

\section{Kristóf Solymosi*, György Kövér, Róbert Romvári}

Kaposvár University, Faculty of Agricultural and Environmental Sciences, H-7400 Kaposvár, Guba S. 40.

\begin{abstract}
Vegetation indices computed from remote sensing data became key components of agricultural monitoring and assessment. With the help of these indices, the difference of vegetational and other land covers can be contrasted and many useful and applicable data can be gathered ranging from vegetation health to growth dynamics among others. In recent decades, starting from the first Landsat satellite, a huge number of VIs were developed in order to be able to effectively monitor vegetation - the reason for the immense number is due to the fact that every sensor, topographic, geographic, vegetative and atmospheric feature is different, and more so are their combinations. This is the reason why there is no unified spectral band mathematical formula. The aim of this short overview is to provide the reader insight of the main vegetation indices (VIs) that have been used in scientific literature and their development over the last 40 years.
\end{abstract}

Keywords - vegetation indices, NDVI, VI, VIs, soil line, SAVI, ARVI, GEMI, VDVI

\section{INTRODUCTION}

Monitoring and assessment of vegetation were always distinctive fields in agriculture. With the help of passive (meaning the source of radiation is the Sun, thus with diffused sunlight) remote sensing, experts and even farmers gain the ability to get information about the plant cover without using excessive destructive methods. In this context, the expression of remote sensing (RS) is used in measuring reflectance in different spectral ranges (bands). Other than that, RS is the term of gathering and processing information from objetcs and phenomena without direct physical contact (Balázsik, 2010).

The usual spectral ranges used in RS of vegetation are bands in the red part of the visible spectrum (wavelength of appr. 0.6-0.7 $\mu \mathrm{m}$ ) and near infrared (NIR, appr. 0.7-1.4 $\mu \mathrm{m}$ ), because they contain about $90 \%$ of the information relating to vegetation (Baret et al., 1989). The biophysical aspect of this is contributed to the fact that visible radiation (appr. $0,4 \mu \mathrm{m}$ to $0,7 \mu \mathrm{m}$ ) is absorbed by leaf pigment cells (chlorophyll-a, chlorofill-b and carotinoids), while radiation in NIR $(0,7 \mu \mathrm{m}$ to $1,4 \mu \mathrm{m})$ is strongly reflected by inner leaf cellular structures. Therefore vegetative covers can be distinguished by their spectral behavior in relation to ground elements and soils by measuring and 
quantifying the difference of the two spectral bands, and that is the basis of a VI (Major et al., 1990; Bannari et al, 1995).

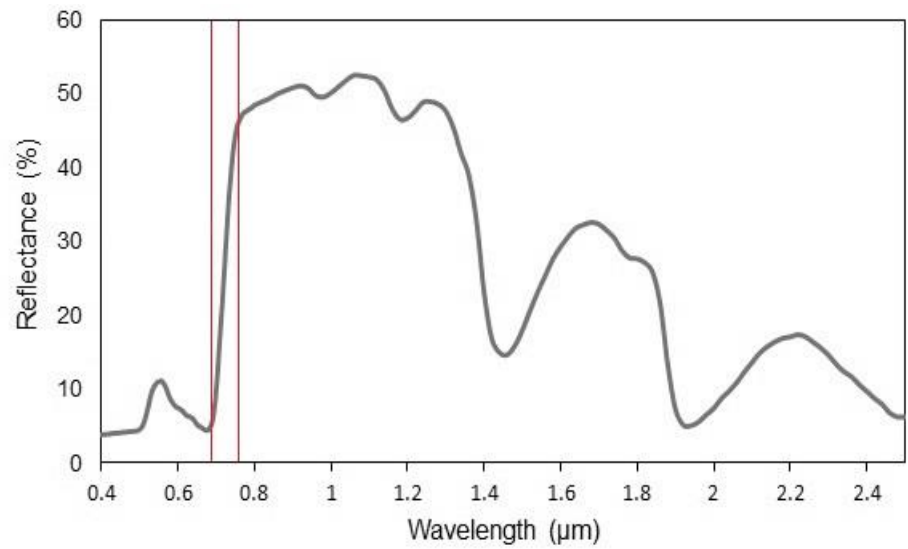

Figure 1: Typical spectral response of plants with indication of Red Edge region

(source: Introduction to Remote Sensing, Humboldt State University)

A vegetation index is usually a mathematical combination of a red and near infrared channel which are detected by a sensor. The reason behind the usual usage of these two bands is the fact that the biggest difference in reflectance is comprised between them (the inbetween region is also called Red Edge, i.e. the inflection point between $0,65 \mu \mathrm{m}$ and $0,75 \mu \mathrm{m}$, as seen on Figure 1). The formula of such an index is the separating factor between VIs and their usability, and the exact computation is done with the digital numbers (or relative reflectances) of image pixels. An index is a number measuring the intensity of a phenomenon that is often too complex to be broken down into easily understandable factors. This is the case for remote sensing of vegetation, because it is generally difficult to make the decomposition for signals observed on RS images. (Bannari et al., 1995) Yet, even a well documented vegetation index is usually hard to interpret (questionable correlation with vegetative cover) and to compare (due to sensor, atmospheric and tomographic differences).

It is worth mentioning that satellite-based remote sensing has been operational since the first Landsat mission (1972). Nowadays, there is a huge number of satellites that are constantly watching the globe, and among them there are a handful of examples which are open access - examples are the 
latest multispectral Landsat satellites and ESA's Sentinel missions. Furthermore, aerial photography and more specifically unmanned aerial vehicles (UAVs) extended with multi- and hyperspectral cameras (also called Unmanned Aerial Systems, UASs) are becoming more numerous and affordable each year giving access to temporal and spatial resolutions not seen before compared to satellites based on today's technology.

The aim of this article is to give an overview of significant, mostly ratiobased vegetation indices found in scientific literature in historical order and in a short manner, and to assess their development throughout the last four decades. Nowadays, classification of VIs is affected by technological advancement as modern sensors allow us to gather more precise data. Thus, narrow band (meaning the data is less scattered but also of lesser amount) indices are distinguished from broad band ones. In fact, narrow bands (such as bands at the red edge positions) can be used singularly to acquire applicable information of vegetation. The main differentiating factor between broad and narrow bands lies in their applicability: while high spectral resolution means very precies and compact data, the range of interpretation is also smaller, due to the fact that the gathered information is very specific. On the other hand, broad band indices can be more universally applied to plant assesment but their specificallity - because of the bulk information - is low. The choice between them has to be made every time, whether it be scientific purpose or general farm management. In the article, we avoid the differentiatiation of narrow and broad bands, thus we use a more traditional approach of discerning vegetation indices.

Indices mentioned here are checked and referenced in the online database, https://www.indexdatabase.de/.

\section{HISTORY OF VEGETATION INDICES}

One of the first researches conducted in the topic of reflective properties of plants was done by Wilstatter and Stoll in 1913. However, the creation of the first vegetation index was prior to the launch of the first Landsat satellite as stated by Mróz and Sobieraj, (2004). The first two VIs were simple ratios of bands Red and NIR (Near Infrared), the Ratio Vegetation Index (RVI) and the Vegetation Index Number (VIN). VIN is also called the Simple Ratio (SR).

$$
\mathrm{RVI}=\frac{\mathrm{RED}}{\mathrm{NIR}}
$$




$$
\mathrm{VIN}=\frac{\mathrm{NIR}}{\mathrm{RED}}
$$

In spite of the simplicity of the formulas, sources differ on their origins. However, the earliest mention was by C.F. Jordan in 1969, according to Xue and Su (2017).

The sole purpose of them is to contrast the difference between vegetation and other ground objects, and they are still used even today (mostly in comparisons, such as in Huete and Jackson, 1987) as they are easy to compute and interpret. Ratio-based indices have the huge benefit of eliminating disturbing factors that affect all bands in the same way (such as topography, Baret and Guyot, 1991). However, if the vegetation is sparse and soil reflectances come in action, they become near useless and these indices do not have normal distribution either (Bannari et al., 1995).

One of the oldest, yet even nowadays among the most used indices wordwide is the Normalised Difference Vegetation Index (NDVI) which was created by Rouse et al. in 1974 (a). It could be viewed as the enhanced and normalised version of VIN (SR), as it is its linear function (Perry and Lautenschlager, 1984).

$$
\mathrm{NDVI}=\frac{\mathrm{NIR}-\mathrm{RED}}{\mathrm{NIR}+\mathrm{RED}}=\frac{V I N-1}{V I N+1}
$$

The success of NDVI is through its normalization (index range is from - 1 to 1) process that enables the user to easily explain and compare the results. Beside that, as it is also a ratio-based index the same benefits apply here as well. However, it does not correct atmospheric effects, and has a short dynamic range - underestimates sparse vegetation because of soil effects and rapidly saturates at very high vegetation density because it weighs the red and nearinfrared bands the same in its formula. The NDVI has been successfully applied in a great number of studies in the last four decades, ranging from vegetation monitoring (Santos and Negri, 1996; Radoslaw, 2010; Yengoh et al., 2014), classification (Julien et al., 2011; Havasi and Benő, 2012;) to estimation of different vegetational traits (i.e. chlorophyll and nitrogen content, plant height; Prince and Tucker, 1986; Deblonde and Cihlar, 1993; Payero et al. 2004; Ambrus et al, 2015).

The fact that NDVI lacks normal distribution and has negative values, in the same year of the developement of NDVI $(1974, \mathrm{~b})$, Rouse et al. created the 
Transformed Vegetation Index (TVI) to eliminate the aforementioned problems.

$$
\mathrm{TVI}=\sqrt{\mathrm{NDVI}+0.5}
$$

Obviously, if NDVI < -0.5 (very low NDVI values) then it cannot be computed. According to Perry and Lautenschlager (1984), TVI could still be negative so they improved it (some sources list it as TVI2).

$$
\mathrm{TVI} 2=\frac{\mathrm{NDVI}+0.5}{|\mathrm{NDVI}+0.5|} * \sqrt{|\mathrm{NDVI}+0.5|}
$$

In 1976, Kauth and Thomas, based on the processing of Landsat images, developed the method of Tasseled Cap Transformation (TCT). It is different from the aforementioned indices in the fact that it converses and compacts the original bands into fewer ones leaving only the useful information in them The results of the transformation are four computed bands (as outputs), namely the Soil Brightness Index (SBI), Green Vegetation Index (GVI). Yellow Vegetation Index (YVI) and the Non-Such Index (NSI, which contains the noise from the image) (Xue and Su, 2017). It is worth mentioning that in 2017, Nedokov successfully applied the TCT on Sentinel-2 images and reported remarkable results.

One of the main problems of ratio-based indices is the fact that they are not taken into account noise coming from sparsely vegetated areas (i.g. soil reflectance). In light of this, after prior research of soil effects, Richardson and Wiegand proposed the Perpendicular Vegetation Index (PVI) in 1977 which was perfected by the work of Jackson et al. in 1980 fformula 6 and 7 accodingly).

$$
\begin{gathered}
\mathrm{PVI}=\sqrt{\left(\mathrm{RED}_{\text {soil }}+\mathrm{RED}_{\mathrm{veg}}\right)^{2}+\left(\mathrm{NIR}_{\text {soil }}+\mathrm{NIR}_{\mathrm{veg}}\right)^{2}} \\
\mathrm{PVI}=\frac{(\mathrm{NIR}-\mathrm{aRED}-\mathrm{b})}{\sqrt{\mathrm{a}^{2}}+1}
\end{gathered}
$$

Where 'a' and 'b' are the slope and intercept of the 'soil line' (Figure 2). Richardson and Wiegand (1977) noted that pixels representing soils tend to align in RED-NIR space on the same line, and they named it the Soil Background Line (SBL) which came to be known as the soil line. Vegetation indices that utilize 
the soil line parameters represent a different category of ratio- (or slope-) based indices. The gerenal formula of the soil line concept can be seen on Formula 8 (Bannari et al., 1995).

$$
\mathrm{NIR}=\mathrm{aR}+\mathrm{b}
$$

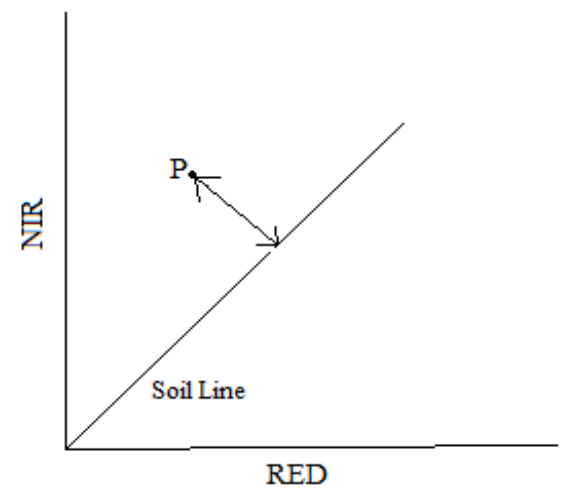

Figure 2: PVI index and the soil line (source: http://a-a-r-s.org)

The sole purpose of PVI is to measure the prependicular distance of vegetation pixels from the soil line (Figure 2) as Richardson and Wiegand also noted that pixels representing vegetation are always on the left side of the SBL (and pixels representing water bodies are on its right side). However, studies showed that PVI is still very prone to miscalculations due to variable soil effects, and the determination the exact parameters of a given soil line is challenging (i.g. Major et al., 1990; Huete, 1985). Yet, it is used quite often in comparisons, classifications and biomass-estimations (such as in: Huete et al., 1985; Major et al., 1990; Garey et al., 2004, Payero et al., 2004; Wenlong, 2009).

One of the most straightforward vegetation indices is the simple difference of the bands RED-NIR, which is called the Differenced Vegetation Index (DVI).

$$
\text { DVI }=\text { NIR }- \text { RED }
$$

As with RVI and VIN, sources differ on the origins of DVI, but most of them agree on the fact that it was first mentioned with Landsat-bands in the works of Richardson and Wiegand in 1977. It is still used nowadays due to its simplicity (faster computational times) mainly in comparisons and vegetation monitoring (Bannari et al., 1995; Barzegar et al., 2015). 
In 1988, mostly because of the deficiencies of NDVI and PVI in evaluating the soil reflectances, Huete proposed the Soil Adjusted Vegetation Index (SAVI, Formula 10). It is a compromise between the two main types of VIs (slopebased and orthogonal indices) as it contains a non-linear factor (L) which correlates with vegetation density (Huete, 1988).

$$
\mathrm{SAVI}=\frac{\mathrm{NIR}-\mathrm{RED}}{\mathrm{NIR}+\mathrm{RED}+\mathrm{L}}(1+L)
$$

It is apparent if L equals 0 , then SAVI equals NDVI. According to Huete, when $\mathrm{L}$ is 0.5 ( $\mathrm{L}$ can range from 0 to 1 ) it permits the best adjustment against canopy backscattering, but the general rule is that the denser the vegetation, the closer $\mathrm{L}$ is to 1 . So in order to have adequate results, the user needs to evaluate the density of vegetation on a given area and pair it with the correct L value from literature or prior research. However, in many cases the density of vegetation is the one that we are aiming to determine with VIs. So in order to address this problem Qi et al. proposed the Modified Soil Adjusted Vegetation Index (MSAVI) in 1994 that varies with the amount of vegetation present on the picture (Formula 11).

$$
\text { MSAVI }=\frac{2 \mathrm{NIR}+1-\sqrt{(2 \mathrm{NIR}+1)^{2}-8(\mathrm{NIR}-\mathrm{R})}}{2}
$$

There are many variations of SAVI, but one of the most influential is the Transformed Soil Adjusted Vegetation Index (TSAVI) created by Baret et al. in 1989 (and perfected it in 1991). It uses the parameters from the soil line (Formula 8) which makes it robust according to Baret.

$$
\text { TSAVI }=\frac{(\mathrm{a}(\mathrm{NIR}-\mathrm{aR}-\mathrm{b}))}{(\mathrm{R}+\mathrm{aNIR}-\mathrm{ab})}
$$

Abdou and Huete published of the usability of SAVI and especially TSAVI compared to NDVI as they are independent from the sensor used, and they give better results in differentiating vegetative cover from bare soil (Bannari et al., 1995).

As it has been already mentioned, one of the main problems of NDVI is its narrow dynamic range or small sensitivity. In 1991, Escadafal and Huete addressed this shortcoming by correcting NDVI (and also SAVI) with a factor 
that correlates with soil color. This factor is the Redness Index (RI) and the VI used was corrected with the slope (' $\mathrm{k}$ ') of the linear correlation of RI and the given VI (Formula 12-13; Escadafal and Huete, 1991). Based on the results of the authors, this correction can enhance the sensitivity of NDVI and SAVI.

$$
\begin{gathered}
\mathrm{RI}=\frac{\mathrm{RED}-\mathrm{GREEN}}{\mathrm{RED}+\mathrm{GREEN}} \\
\mathrm{VI}_{\text {corr }}=\mathrm{VI}-\mathrm{kRI}
\end{gathered}
$$

When the vegetation is sparse, the VI used is greatly influenced by the soil parameters. However, atmospherical factors always play a remarkable role, and researchers started to create vegetation indices which deal with this issue starting from the 1990's. One of the first and most significant was the Atmospherically Resistant Vegetation Index (ARVI) in 1992 by Kaufman and Tanré. Their explanation is that in general the atmosphere increases the reflectance of the red bands, and decreases it on the near-infrared channels, therefore they implemented a self-correcting factor for the former into the formula.

$$
\begin{gathered}
\mathrm{ARVI}=\frac{\mathrm{NIR}-\mathrm{RB}}{\mathrm{NIR}+\mathrm{RB}} \\
R B=R-\gamma(R-B) \\
\gamma=\frac{\rho_{a-r}}{\rho_{a-b}-\rho_{a-r}}
\end{gathered}
$$

$\mathrm{RB}$ is the corrected difference of the red and blue channel, and $\gamma$ is the selfcorrecting factor $\left(\rho_{\mathrm{a}-\mathrm{b}}\right.$ and $\rho_{\mathrm{a}-\mathrm{r}}$ are components of the atmospherical reflectance in the blue and red channel accordingly). Of course, if $\gamma=0$, then ARVI equals NDVI. According to Kaufman and Tanré, if no atmospherical data is present a priori, than $\gamma=1$ is a good choice for better adjustments (Kaufman and Tanré, 1992). There are many versions of ARVI, and the RB factor in its formula inspired a number of researchers to create new VIs with it (or to implement it into former ones). However, precisely defining the value of $\gamma$ can be difficult, hence ARVI is mainly used in comparisons, and not as a main VI in researches (Xue and $\mathrm{Su}, 2017$ ).

Based on the analisation of satellite images, Pinty and Verstrate proposed a new vegetation index in the same year as ARVI (1992) that - according to the 
authors - deals with atmospherical effects, and is easier to compute than ARVI. It is called the Global Environment Monitoring Index (GEMI), and as its name suggests, it is designed for global monitoring of vegetation.

$$
\begin{gathered}
\text { GEMI }=\frac{\eta(1-0.25 \eta)-(\text { RED }-0.125)}{(1-\text { RED })} \\
\eta=\frac{\left(2\left(\mathrm{NIR}^{2}-\mathrm{RED}^{2}\right)+1.5 \mathrm{NIR}+0.5 \mathrm{RED}\right)}{\mathrm{NIR}+\mathrm{RED}+0.5}
\end{gathered}
$$

GEMI is aimed to be more sensitive than NDVI, however many studies showed that (i.e.: Bannari et al., 1994) sparse vegetation can seriously alter the index values due to reflectance coming from soils. In spite of it, GEMI is still widely used today in studies that need information of vegetation on a global scale.

One of the first VIs that combined the elimination of atmospherical and soil effects in one single vegetation index was the Transformed Soil Atmospherically Resistant Vegetation Index (TSARVI). As the name suggest, TSARVI is the combination of TSAVI and ARVI, and as such, in the formula of TSAVI the red channel was replaced by RB (Formula 16; according to Rondeaux et al, 1996). In scientific literature there is little mention of TSARVI, and Myneni and Asrar in 1994 showed that the combination of TSAVI and ARVI does not reach the same level of correction as their individual parts.

In 1995, Liu and Huete created a vegetation index that - similarly to TSARVI - tries to eliminate disturbing factors coming both from soil and atmospheric effects. The Enhanced Vegetation Index (EVI) is so called because the aim was to enhance NDVI. The formula was designed with Landsat bands, but the authors give a generalised version of it as well (Formula 20-21).

$$
\begin{aligned}
\mathrm{EVI} & =2.5 * \frac{\left(\mathrm{TM}_{4}-\mathrm{TM}_{3}\right)(1+\mathrm{L})}{\mathrm{TM}_{4}-\left(\mathrm{C}_{1} * \mathrm{TM}_{3}\right)+\left(\mathrm{C}_{2} * \mathrm{TM}\right)+\mathrm{L}} \\
\mathrm{EVI} & =2.5 * \frac{\mathrm{NIR}-\mathrm{RED}}{\mathrm{NIR}+\left(\mathrm{C}_{1} * \mathrm{RED}\right)-\left(\mathrm{C}_{2} * \mathrm{BLUE}\right)+\mathrm{L}}
\end{aligned}
$$

TM (Thermatic Mapper) stands for the Landsat band used, factor $\mathrm{L}$ is the same concept as in SAVI, and the two constant values $\left(\mathrm{C}_{1}, \mathrm{C}_{2}\right)$ are 6 and 7.5 
respectively. Unlike TSARVI, EVI has ample mention in scientific literature, and is still used nowadays in various studies.

Another widely used index (created in 1996 by Gao) is the Normalised Difference Water Index (NDWI) that uses two infrared bands (a NIR band at around $840-860 \mathrm{~nm}$, and an infrared band at 1630-1660 nm) in a formula very simliar to NDVI.

$$
\mathrm{NDWI}=\frac{\mathrm{NIR}-\mathrm{IR}}{\mathrm{NIR}+\mathrm{IR}}
$$

It is a measure of liquid water molecules in vegetation canopy that interact with solar radiation, thus it indicates and enhances water content of canopy making the user be able to assess canopy health and - for example - stresslevels.

The Chlorophyll Absorption Ratio Index (CARI) has many different variations, but all rely on the fact that spectral response of chloropyll content of leaves is constant in spite of variable leaf attributes (Kim et al, 1994). In 2000, Daughtry et al. improved CARI to Modified Chlorophyll Absorption Ratio Index, (MCARI) which - according to them - is more sensitive to leaf chlorophyll content.

$$
\operatorname{MCARI}=\frac{1.5[2.5(\mathrm{NIR}-\mathrm{RED})-1.3(\mathrm{NIR}-\mathrm{GREEN})]}{\sqrt{(2 N I R+1)^{2}-(6 N I R-5 R E D)-0.5}}
$$

Another approach of improving the NDVI can be seen in 2004 by Gitelson. When the LAI (Leaf Area Index) is high, NDVI loses its accuracy due to diminishing NIR reflectance. Thus, he proposed a correctional factor $(\alpha)$ for NIR that correlates with LAI or VF (Vegetation Fraction) and created a new vegetation index, the Wide Dynamic Range Vegetation Index (WDRVI).

$$
\text { WDRVI }=\frac{\alpha \mathrm{NIR}-\mathrm{RED}}{\alpha \mathrm{NIR}+\mathrm{RED}}
$$

Starting around from the year 2000, the emergence of vegetation indices using the other visible spectrum bands (mostly green) is apparent. Gitelson in 1996 reasons with the fact that in prior years, researchers were only focusing on the difference between the red and NIR bands to identify vegetation, not on evolution's choice of identification of plants, the green channel. Novel examples of this are GARI (or GARVI, Green Atmopherically Resistant 
Vegetation Index developed with the subtitution of red with green channel in ARVI) and the Green NDVI (using a green channel instead of red one in the formula of NDVI). The authors claim that using the green channel (that highly correlates with chlorophyll content) can make these formulas at least five times more sensitive to existing chlorophyll in vegetation, and can make them have a wider dynamic range (Gitelson et al, 1996). Another example of this is the Visible Atmospherically Resistant Vegetation Index (VARI) by Gitelson et al in 2002.

$$
\mathrm{VARI}=\frac{\text { GREEN }- \text { RED }}{\text { GREEN }+ \text { RED }- \text { BLUE }}
$$

According to the authors, the red/NIR ratio is less effective to evaluate the vegetation fraction when the VF is high (because NIR reflectance saturates at higher fractions of vegetation), in contrast the green/red ratio moves with the vegetation fraction in very high correlation. Besides, they realised that by adding a blue channel to the formula as a self-correcting factor for the atmosphere, they could increase the correlation of the index with VF.

Another example of the emerge of visible vegetation indices is the usage of the Green Difference Vegetation Index (GDVI) which was developed in 1979 by Tucker. It is very similar to DVI (Formula 9), however it uses a green channel instead of a red one. The GDVI has sparse mention prior to the publication of Sripada et al. (2005) who successfully created a model of optimal nitrogen fertilisation using the GDVI.

GDVI (1979) is not to be confused with the GDVI (Generalised Difference Vegetation Index) of $W u$ (2014), where the latter is the improvement of NDVI through exponentiation.

$$
\text { GDVI }=\frac{\mathrm{SR}^{\mathrm{n}}-1}{\mathrm{SR}^{\mathrm{n}}+1}=\frac{\mathrm{NIR}^{\mathrm{n}}-\mathrm{RED}^{\mathrm{n}}}{\mathrm{NIR}^{\mathrm{n}}+\mathrm{RED}^{\mathrm{n}}}
$$

' $n$ ' is an integer from 1 to n. GDVI (2014) is proven to be a lot more sensitive than NDVI, SAVI, WDRVI and SARVI, and has a greater range as well.

One of the latest and most promising indices is the Visible Band-Difference Vegetation Index (VDVI, Wang et al., 2015).

$$
\text { VDVI }=\frac{2(\text { GREEN }- \text { RED }- \text { BLUE })}{2(\text { GREEN }+ \text { RED }+ \text { BLUE })}
$$


Compared to other visible light indices (NGRDI, NGBDI, RGRI]), it performs much better when using UAV imagery, reported accuracy is over $90 \%$ (Xue and $S u, 2017$ ). Thus, it holds great promise for agriculture and for - for example farmers using simple, visible light unmanned aerial systems.

\section{SUMMARY}

According to Jackson et al. (1983), the ideal vegetation index can be described as an index which is 'particularly sensitive to vegetative covers, insensitive to soil brightness, insensitive to soil color, little affected by atmospheric effects, environmental effects and solar illumination geometry and sensor viewing conditions'. Unfortunately, the ideal one is still to be created as every above mentioned circumtence is different when a vegetation index is used.

If we take a look at the timeline of VIs, the first ones created (which are very much used nowadays due to their simplicity, i.e.NDVI) were the staples of the other later vegetation indices, as they originate from plant biophysics without correcting with any disturbing features. Thus, these simple and mostly slopebased (as they practically measure the slope of vegetation isolines) indices are still the basis of every research done in the topic.

Starting from the 1980's, the attention of remote sensing scientists were directed at the problem of soil reflectance. Thus, the soil line concept was born, and with it angular vegetation indices (such as the PVI). Later that decade, soil adjusted NDVI-based indices were also created (SAVI, MSAVI, TSAVI).

However, there was still an untended problem, the atmospheric disturbances. In the 1990's, the focus shifted, and it lead to atmospherically corrected indices, such as the ARVI, EVI, GEMI and other derivates. As we were moving towards the next millenium more complex attempts to create the ultimate index (soil and atmopherical corrections in one VI) were conducted, not reaching the perfect solution yet.

Today, the perfection of older indices are still in work, and the emergance of VIs that are utlising the visible spectrum broadens the possibilities of creating effective vegetation indices for every user, even for those that do not possess multi- and hyperspectral cameras. This is supported by the fact that commercial cameras and drones are emerging to be more available for everybody.

Also, due to the above mentioned technical advancements and ongoing researches, our knowledge of vegetation spectrums are widening. This led to various narrow bands that try to reflect core information about vegetation. The future of vegetation monitoring may lie in these narrow bands, thus in hyperspectral cameras, as data-gathering can be tailored according to the 
types and phenological stages of plants based on prior research. However, as already stated above, usage of broader bands means a higher range of interpretation as well.

\section{ACKNOWLEDGEMENTS}

The work is supported by the EFOP-3.6.3-VEKOP-16-2017-00008 project. The project is co-financed by the European Union and the European Social Fund.

\section{REFERENCES}

Baret, E., Guyot, G., Major, D. J., (1989): TSAVI: A vegetation index which minimizes soil brightness effects on LAI and APAR estimation. Proceedings of the 12th Canadian Symposium on Remote Sensing, Vancouver, Canada, p. 1355-1358.

Major, D. J., Baret, F., Guyot, G., (1990): A ratio vegetation index adjusted for soil brightness. International Journal of Remote Sensing 11 (5), p. 727-740.

Sripada, R. P., Ronnie W., Heiniger, J., White, G., Meijer, A.D., (2006): Aerial Color Infrared Photography for Determining Early In-Season Nitrogen Requirements in Corn. Agronomy Journal 98 (4), p. 96877. DOI: 10.2134 /agronj2005.0200

Ambrus, A., Burai, P., Lénárt, Cs., Enyedi, P., Kovács, Z., (2015): Estimating biomass of winter wheat using narrowband vegetation indices for precision agriculture, Journal of Central European Green Innovation 3 (2) p. 13-22.

Balázsik, V., (2010): Fotogrammetria 1. : A távérzékelés fogalma, a fotogrammetria és a távérzékelés kapcsolata - Nyugat-magyarországi Egyetem Geoinformatikai Kar, p. 1-18.

Bannari, A., Morin, D., Bonn, F., Huete, A.R., (1995): A Review of Vegetation Indices; Remote Sensing Reviews, Vol. 13, p. 95-120.

Bannari, A., Morin, D., He, D. C., (1994): High spatial and spectral resolution remote sensing for the management of the urban environment. First International Airborne Remote Sensing Conference and Exhibition, Strasbourg, France, vol. III, p. 247-260.

Baret, E., Guyot, G., (1991): Potentials and limits of vegetation indices for LAI and APAR assessment. Remote Sensing of Environment 35, p. 161-173.

Baret, E., Guyot, G., Major, D. J., (1989): TSAVI: A vegetation index which minimizes soil brightness effects on LAI and APAR estimation. Proceedings of the 12th Canadian Symposium on Remote Sensing, Vancouver, Canada, p. 1355-1358.

Barzegar, M., Hamid, E., Abbas, K., (2015): Comparison of Different Vegetation Indices for Very HighResolution Images, Specific Case UltraCam-D Imagery. International Archives of the Photogrammetry, Remote Sensing and Spatial Information Sciences - ISPRS Archives 40 (1W5), p. 97-104. DOI: 10.5194/isprsarchives-XL-1-W5-97-2015

Daughtry, C.S.T., Walthall, C.L., Kim, M.S., De Colstoun, E.B., McMurtrey, J.E. III, (2000): Estimating corn leaf chlorophyll concentration from leaf and canopy reflectance, Remote Sensing of Environment, vol. 74, no. 2, p. 229-239.

Deblonde, G., Cihlar, J., (1993): A multiyear analysis of the relationship between surface environmental variables and NDVI over the Canadian landmass, Remote Sensing Reviews 7, p. 151-177.

Escadafal, R., Huete, A. R., (1991): Étude des propriétés spectrales des sols arides appliquée à l'amélioration des indices de végétation obtenus par télédétection, CR Acad. Sci. Paris 312 (2), p. 1385-1391. 
Gao, B. C., (1996): NDWI - A normalized difference water index for remote sensing of vegetation liquid water from space. Remote Sensing of Environment, 58(3), p. 257-266. DOI: 10.1016/S0034$\underline{\text { 4257(96)00067-3 }}$

Garey, A., Sabbagh, G.J., Searcy, S.W., Yang, C., (2004): An Automated Soil Line Identification Routine for Remotely Sensed Images, Soil Science Society of America Journal 68 (4), p. 1326. DOI: $\underline{10.2136 / \text { sssaj2004.1326 }}$

Gitelson, A. A., Kaufman, Y. J., Merzlyak, M. N., (1996): Use of a green channel in remote sensing of global vegetation from EOS-MODIS. Remote Sensing of Environment, 58(3), p. 289-298. DOI: $\underline{10.1016 / S 0034-4257(96) 00072-7}$

Gitelson, A. A., Kaufman, Y. J., Stark, R., Rundquist, D., (2002): Novel algorithms for remote estimation of vegetation fraction. Remote Sensing of Environment, 80(1), p. 76-87. DOI: 10.1016/S0034$\underline{4257(01) 00289-9}$

Gitelson, A.A., (2004): Wide dynamic range vegetation index for remote quantifcation of biophysical characteristics of vegetation, Journal of Plant Physiology, vol. 161, no. 2, p. 165-173.

GSP 216: Introduction to Remote Sensing, Humboldt State University, Available online at: http://gsp.humboldt.edu/OLM/Courses/GSP 216 Online/lesson2-1/reflectance.html

Havasi I., Benő D., (2012): Hagyományos és Fuzzy nem felügyelt osztályozás összehasonlítása vegetációs index példáján, Tájökológiai lapok, 10(1), p. 115-123.

Huete, A. R., Jackson, R.D., Post, D.F., (1985): Spectral response of a plant canopy with different soil backgrounds. Remote Sensing of Environment, Volume 17(1), p. 37-53.

Huete, A. R., (1988): A soil-adjusted vegetation index (SAVI). Remote Sensing of Environment 25, p. 295-309.

Huete, A. R., Jackson, R. D., (1987): Suitability of Spectral Indices for Evaluating Vegetation Characteristics on Arid Rangelands, 232, p. 213-232.

Jackson, R. D., Pinter, P. J., Paul, J., Reginato, R.J., Robert, J., Idso, S. B., (1980): Hand-held radiometry. Agricultural Reviews and Manuals ARM-W-19. Oakland, California: U.S. Department of Agriculture, Science and Education Administration.

Jackson, R. D., Slater, P. N., Pinter, P. J., (1983): Discrimination of growth and water stress in wheat by various vegetation indices through clear and turbid atmospheres. Remote Sensing of Environment 13, p. 187-208.

Julien, Y., Sobrino, J. A., Mattar. C., Ruescas, A. B., Jimenez-munoz, J. C., Soria, G., Hidalgo, V., Atitar, M., Franch, B., Cuenca, J., (2011): Temporal analysis of normalized difference vegetation index (NDVI) and land surface temperature (LST) parameters to detect changes in the Iberian land cover between 1981 and 2001. International Journal of Remote Sensing, Vol. 32, No. 7, 10 April 2011, p. 2057-2068.

Kaufman, Y. J., Tanré, D., (1992): Atmospherically Resistant Vegetation Index (ARVI) for EOS-MODIS. IEEE Transactions on Geoscience and Remote Sensing 30 (2), p. 261-270.

Kauth, R.J., Tomas, G., (1976): The tasselled cap-a graphic description of the spectral-temporal development of agricultural crops as seen by landsat, in Proceedings of the LARS Symposia, p. 159.

Kim, M.S., Daughtry, C., Chappelle, E., McMurtrey, J., Walthall, C., (1994): The use of high spectral resolution bands for estimating absorbed photosynthetically active radiation (a par), in Proceedings of the 6th International Symposium on Physical Measurements and Signatures in Remote Sensing, CNES, Phoenix, Ariz, USA, January

Liu H.Q., Huete A., (1995): Feedback based modifcation of the NDVI to minimize canopy background and atmospheric noise, IEEE Transactions on Geoscience and Remote Sensing, vol. 33, no. 2, p. 457465.

Major, D.J., Baret, F., Guyot, G., (1990): A ratio vegetation index adjusted for soil brightness, International Journal of Remote Sensing, vol. 11, no. 5, p. 727-740. 
Mróz, M., Sobieraj, A., (2004): Comparison of several vegetation Indices calculated on the basis Of a seasonal spot xs time series, And their suitability for land cover And agricultural crop identification. Technical Sciences, 7, p. 40-68.

Myneni, R. B., Asrar G., (1994): Atmospheric effects and spectral vegetation indices, Remote Sens. Environ. 47, p. 390-402.

Nedokov, R., (2017): Orthogonal Transformation of Sentinel-2, Comptes rendus de l'Acad'emie bulgare des Sciences, 70(5), p. 687-692.

Payero, J.O., Neale, C.M.U., Wright. J.L., (2004): Comparison of eleven vegetation indices for Estimating plant height of alfalfa and grass. Applied Engineering in Agriculture Vol. 20(3), p. 385-393.

Perry, C. R., Lautenschlager, L. F., (1984): Functional equivalence of spectral vegetation indices. Remote Sensing of Environment 14, p. 169-182.

Pinty, B., Verstraete, M. M., (1992): GEMI: a non-linear index to monitor global vegetation from satellites. Vegetatio 101, p. 15-20.

Prince, S. D., Tucker, C. J., (1986): Satellite remote sensing of rangelands in Botswana. II. NOAA AVHRR and herbaceous vegetation. International Journal of Remote Sensing 7, p. 1555-1570.

Qi, J., Chehbouni, A ., Huete, A.R., Kerr, Y.H., Sorooshian, S., (1994): A modified soil adjusted vegetation index. Remote Sensing of Environment 47, p. 1-25.

Quan, Z., Xianfeng, Z., Miao, J., (2011): Eco-environment variable estimation from remote sensed data and eco-environment assessment: models and system. Acta Botanica Sinica, vol. 47, p. 1073-1080.

Radoslaw, G, (2010): Comparison of vegetation indices to determine their accuracy in predicting spring phenology of Swedish ecosystems. Master Thesis in Physical Geography and Ecosystem Analysis Department of Earth and Ecosystem Sciences, Lund University.

Richardson, A. J., Wiegand, C. L., (1977): Distinguishing vegetation from soil background information. Photogrammetric Engineering and Remote Sensing 43 (12), p. 1541-1552.

Rondeaux, G., Michael S,, Baret, F., (1996): Optimization of Soil-Adjusted Vegetation Indices. Remote Sensing of Environment 55 (2), p. 95-107. DOI: 10.1016/0034-4257(95)00186-7

Rouse, J. W. Jr., Haas, R., Schell, J., Deering, D., $(1974$, a): eune systems in the great plains with erts. NASA Special Publication 351, p. 309.

Rouse, J. W., Haas, R. W., Schell, J. A., Deering, D. W., Harlan, J. C., (1974, b): Monitoring the vernal advancement and retrogradation (Greenwave effect) of natural vegetationa NASA/GSFCT Type III Final Report, Greenbelt, MD, USA

Santos, P., Negri, A., (1996): A Comparison of the Normalized Difference Vegetation Index and Rainfall for the Amazon and Northeastern Brazil. Journal of Applied Meteorology, vol. 36., p. 958-966.

Sripada, R. P., Heiniger, R. W., White, J. G.,, Meijer, A. D., (2006). Aerial color infrared photography for determining early in-season nitrogen requirements in corn. Agronomy Journal, 98(4), 968-977. DOI: $\underline{10.2134 / \text { agronj2005.0200 }}$

Tucker, C. J., (1979): Red and Photographic Infrared Linear Combinations for Monitoring Vegetation. Remote Sensing of Environment 8 (2), p. 127-50. DOI: 10.1016/0034-4257(79)90013-0

Wang, X., Wang, M., Wang, S., Wu, Y., (2015): Extraction of vegetation information from visible unmanned aerial vehicle images. Nongye Gongcheng Xuebao/Transactions of the Chinese Society of Agricultural Engineering, vol. 31, no. 5, p. 152-159.

Wenlong, X. D. L., (2009): Vegetation index controlling the influence of soil reflection. http://www.paper.edu.cn/releasepaper/content/200906-376

Wu, W., (2014): The Generalized Difference Vegetation Index (GDVI) for Dryland Characterization. Remote Sensing 6 (2), p. 1211-33. DOI: $\underline{10.3390 / r s 6021211}$

Xue, J., Su, B., (2017): Significant Remote Sensing Vegetation Indices: A Review of Developments and Applications. Journal of Sensors, Volume 2017, p. 17. 
Yengoh, G.T., Dent, D., Olsson, L., Tengberg, A.E., Tucker, C.J., (2014): The use of the Normalized Difference Vegetation Index (NDVI) to assess land degradation at multiple scales: a review of the current status, future trends, and practical considerations. Final Report, Lund University Center for Sustainability Studies (LUCSUS), and The Scientific and Technical Advisory Panel of the Global Environment Facility (STAP/GEF) 